\title{
Detection of the Phoma pathogens Plenodomus biglobosus subclades 'brassicae' and 'canadensis' on wasabi, and 'canadensis' in Europe
}

\author{
Kevin M. King (1) Jonathan S. West
}

Accepted: 22 November 2021 / Published online: 2 December 2021

(C) The Author(s) 2021

\begin{abstract}
Phoma stem canker / blackleg is an internationally important disease of Brassicas including B. napus (oilseed rape, OSR), caused by multiple genetic subclades of the fungi Plenodomus lingam (formerly Leptosphaeria maculans) and P. biglobosus (L. biglobosa). In Spring 2021, Phoma-like disease symptoms were observed on leaves and stems of Eutrema japonicum (wasabi) crops at three UK sites (Northern Ireland, Southern England and the West Midlands). Fungal isolation from wasabi leaf spots yielded colonies with two distinct phenotypes on potato dextrose agar (PDA). Isolates from the Northern Ireland and Southern England sites had white colonies with abundant pink cirri that were confirmed (based on ITS rDNA, beta tubulin and actin sequences) as P. biglobosus subclade 'canadensis' $(\mathrm{Pbc})$. Those from the West Midlands site, however, had yellow pigmented colonies and were confirmed by sequencing as $P$. biglobosus subclade 'brassicae' (Pbb). Greenhouse pathogenicity testing showed that $\mathrm{Pbb}$ and $\mathrm{Pbc}$ wasabi isolates were pathogenic not only to this host but also OSR, B. oleracea (cabbage), and $B$. rapa (pak choi). Re-isolation of the fungi was attempted and confirmed from lesions that developed on inoculated OSR and wasabi, thus completing
\end{abstract}

\section{K. M. King $(\bowtie) \cdot$ J. S. West}

Biointeractions and Crop Protection Department,

Rothamsted Research, Harpenden, Hertfordshire AL5 2JQ,

UK

e-mail: Kevin.king@rothamsted.ac.uk
Koch's postulates. These findings represent new discoveries for both $\mathrm{Pbb}$ and $\mathrm{Pbc}$ on wasabi, plus for $\mathrm{Pbc}$ in Europe. The crop health implications of these results are briefly considered.

Keywords Blackleg Brassica $\cdot$ Leptosphaeria spp. $\cdot$ Phoma $\cdot$ Plenodomus spp. $\cdot$ Subclade

In Spring 2021, Phoma-like leaf spot symptoms were observed on Eutrema japonicum (wasabi) crops at three geographically distinct UK locations (Northern Ireland, Southern England, and the West Midlands). Lesions were dark brown / black often with chlorotic yellow margins, with larger lesions often coalescing together (Fig. 1A-C). Occasionally, black elongate lesions were present on some petioles, and when stems (rhizomes) were cut open black streaks were sometimes observed running alongside the vascular bundles with black internal lesions evident.

Fungal isolation from lesion margins was attempted by surface sterilization of $\sim 3 \mathrm{~mm}^{2}$ leaf fragments (by rinsing in 70\% ethanol for $30 \mathrm{~s}, 5 \%(\mathrm{w} / \mathrm{w})$ sodium hypochlorite solution for $30 \mathrm{~s}$, and three times in sterile distilled water (SDW)). Leaf fragments were subsequently blotted dry on sterile paper, transferred to potato dextrose agar (PDA) plates (containing $50 \mu \mathrm{g} / \mathrm{mL}$ each of penicillin plus streptomycin sulphate) and incubated at $20{ }^{\circ} \mathrm{C}$ in the dark for 7 days. After this time, emergent colonies were examined under a stereomicroscope, and single hyphal strands 


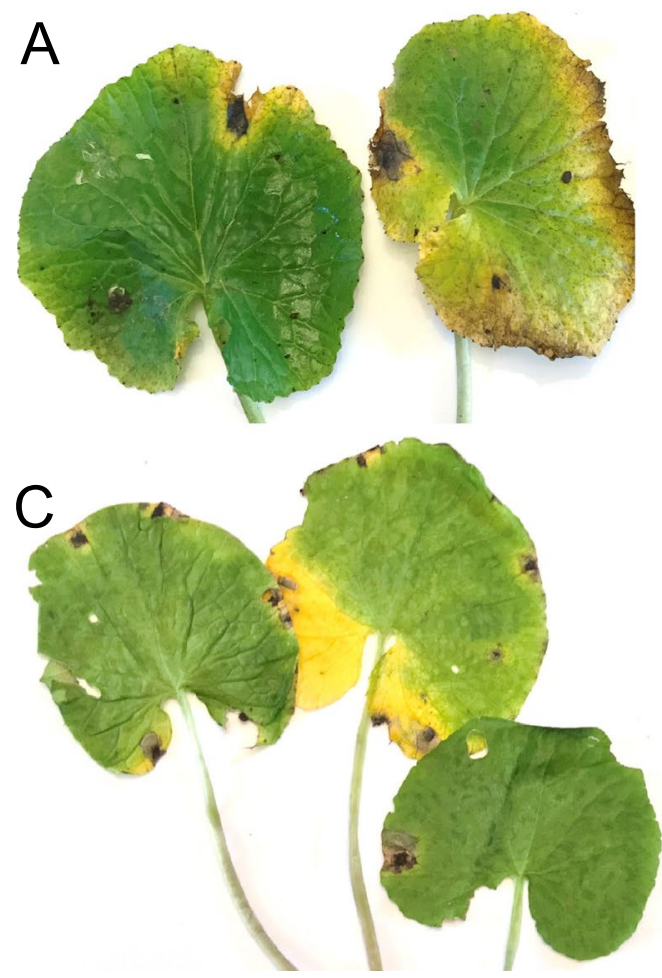

Fig. 1 Isolation of Plenodomus biglobosus subclades 'brassicae' (Pbb) and 'canadensis' (Pbc) from diseased Eutrema japonicum (wasabi) leaves collected from three UK field sites in Spring 2021. Shown are diseased wasabi leaves from (A) Southern England (from which Pbc was isolated), (B) Northern Ireland ( $\mathrm{Pbc}$ isolated), and $(\mathbf{C})$ the West Midlands (Pbb
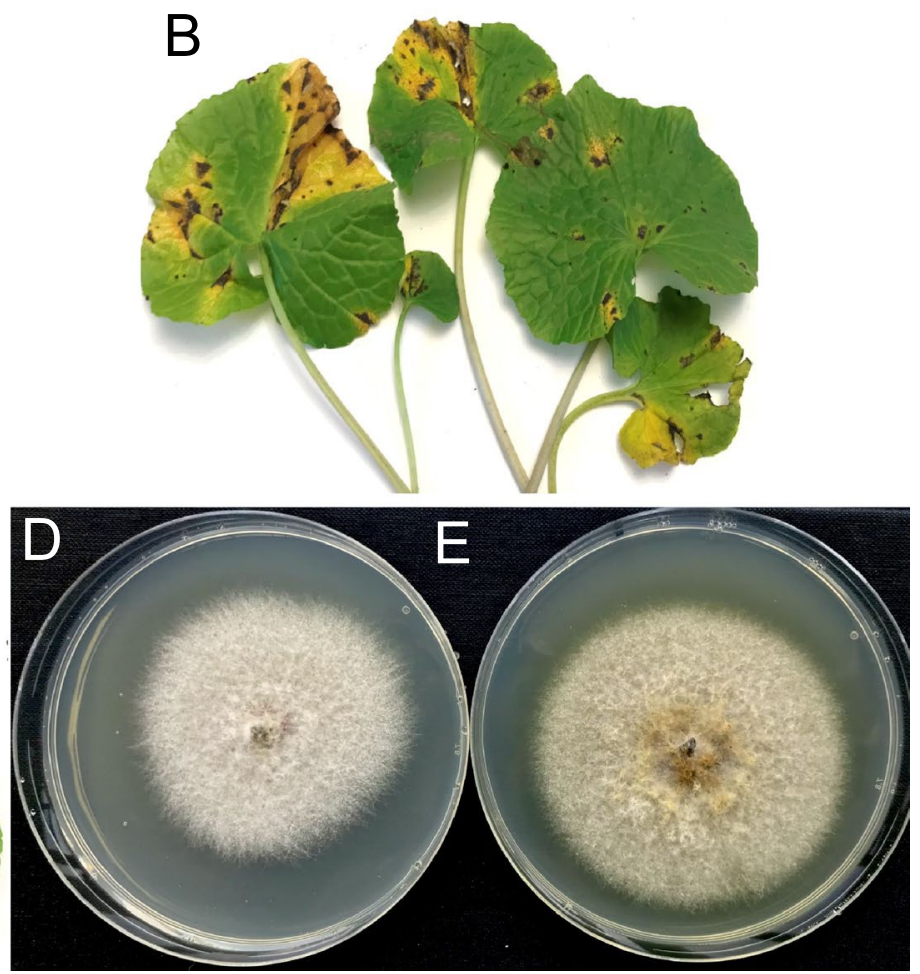

isolated). Representative isolates obtained from the material and grown on potato dextrose agar (PDA) plates for 12 days growth are (D) 21WAS7-1 (from Northern Ireland, white colony with pink oozing cirri evident, Pbc), and (E) 21WAS8-4 (from the West Midlands, yellow pigmented colony, $\mathrm{Pbb}$ )

were amplified via PCR (with a $55{ }^{\circ} \mathrm{C}$ annealing temperature in all cases) for the ITS rDNA (primers ITS4/5), beta tubulin ( $\beta$-tubulin F/R), and actin (Actin F/R) loci (White et al., 1990; Van de Wouw et al., 2008). PCR amplicons were purified and sent for bidirectional sequencing to MWG Eurofins (Germany). Phylogenetic analyses were based on concatenated ITS rDNA, beta tubulin, and actin sequences derived from isolates collected in this study (Table 1), and also reference sequences of all known genetic subclades of $P$. lingam (subclades 'brassicae' and 'lepidii') and P. biglobosus (subclades 'americensis', 'australensis', 'brassicae', 'canadensis', 'erysimii', 'occiaustralensis' and 'thlaspii') sourced from GenBank (see Fig. 2 legend for full details). The analyses revealed that isolates from Southern England and Northern Ireland (21WAS1-2, 21WAS7-1, 21WAS77 ), that had produced white non-pigmented colonies on PDA, as P. biglobosus subclade 'canadensis' 
Table 1 Details of Plenodomus biglobosus isolates from Eutrema japonicum (wasabi) in 2021 examined in this study

\begin{tabular}{|c|c|c|c|c|c|c|c|c|}
\hline \multirow[b]{2}{*}{ Isolate code } & \multirow[b]{2}{*}{ Geographic origin } & \multirow[b]{2}{*}{ Genetic subclade } & \multirow[b]{2}{*}{$\begin{array}{l}\text { Yellow } \\
\text { pigmented } \text { colonies }^{\mathrm{a}}\end{array}$} & \multicolumn{3}{|c|}{$\begin{array}{l}\text { Newly obtained GenBank accession } \\
\text { Nos }\end{array}$} & \multicolumn{2}{|c|}{$\begin{array}{l}\text { Live culture deposit } \\
\text { Nos }\end{array}$} \\
\hline & & & & ITS rDNA & Beta tubulin & Actin & $\mathrm{CABI}^{\mathrm{b}}$ & $\mathrm{CHAP}^{\mathrm{c}}$ \\
\hline $21 \mathrm{WAS} 1-2^{\mathrm{d}}$ & $\begin{array}{l}\text { Southern Eng- } \\
\text { land, UK }\end{array}$ & 'canadensis' & No & OK273900 & OK335038 & OK335043 & - & - \\
\hline 21 WAS7- $1^{\mathrm{d}}$ & $\begin{array}{l}\text { Northern Ireland, } \\
\text { UK }\end{array}$ & 'canadensis' & No & OK273901 & OK335039 & OK335044 & IMI 507211 & CB00116 \\
\hline 21WAS7-7 & $\begin{array}{l}\text { Northern Ireland, } \\
\text { UK }\end{array}$ & 'canadensis' & No & OK273902 & OK335040 & OK335045 & - & - \\
\hline 21 WAS $8-4^{\mathrm{d}}$ & $\begin{array}{l}\text { West Midlands, } \\
\text { UK }\end{array}$ & 'brassicae' & Yes & OK273903 & OK335041 & OK335046 & IMI 507212 & CB00117 \\
\hline 21WAS8-5 & $\begin{array}{l}\text { West Midlands, } \\
\text { UK }\end{array}$ & 'brassicae' & Yes & OK273904 & OK335042 & OK335047 & - & - \\
\hline
\end{tabular}

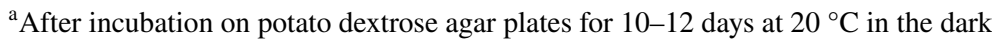

${ }^{\mathrm{b}} \mathrm{CABI}$ GRC: https://www.cabi.org/services/microbial-services/culture-collection-microorganism-supply/grc/

${ }^{\mathrm{c}} \mathrm{CHAP}$ NRC: https://chap-solutions.co.uk/nrc-portal/

${ }^{\mathrm{d}}$ Included in pathogenicity testing

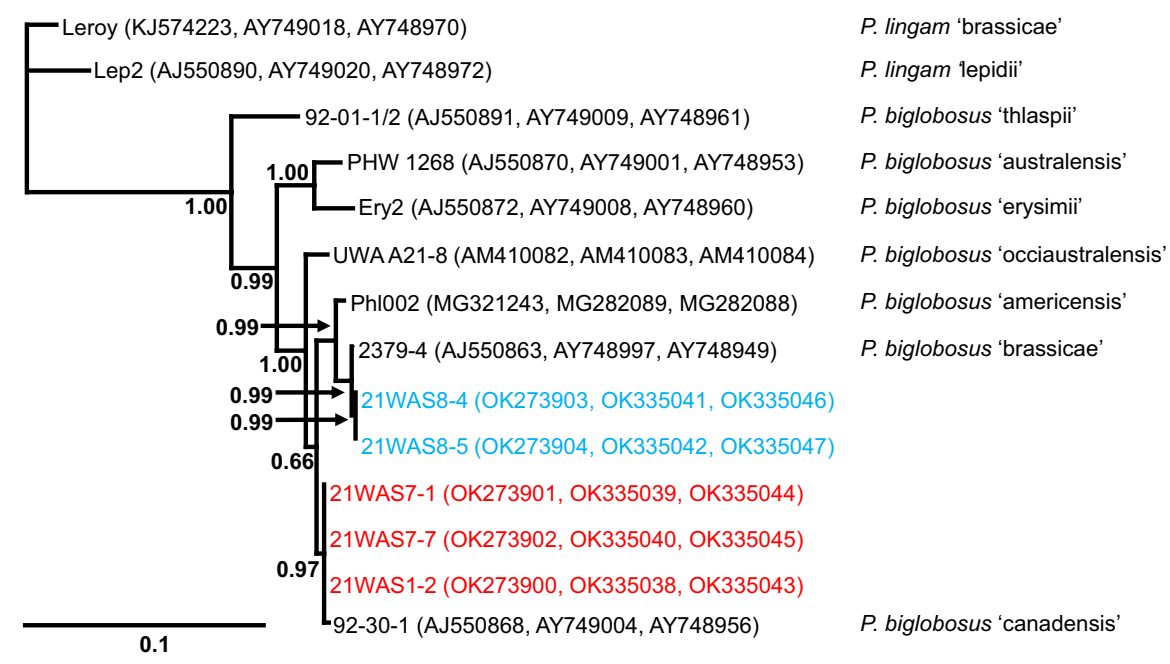

Fig. 2 Bayesian phylogenetic tree (constructed with MrBayes) inferred from concatenated partial ITS rDNA (456 bp), beta tubulin (375 bp), and actin (415 bp) sequences of Plenodomus species. Isolates newly obtained from Eutrema japonicum (wasabi) in the UK in this study were identified as either $P$. biglobosus subclade 'brassicae' (blue) or subclade 'canadensis' (red); newly obtained sequences were deposited onto GenBank (see brackets). Reference sequences from isolates of known genetic subclades of P. lingam and P. biglobosus used in the analyses are indicated to the right, with sequences downloaded from GenBank (see brackets). The tree shown was based on the on the GTR $+\mathrm{I}+\mathrm{G}$ model (determined as optimal via JModelTest), with 1,000,000 MCMC generations and a $25 \%$ burn in. Bayesian posterior probabilities are indicated in bold at nodes. The outgroup for this tree was P. lingam subclade 'brassicae'. The scale bar represents the number of nucleotide substitutions per site 
$(\mathrm{Pbc})$. However, isolates from the West Midlands (21WAS8-4, 21WAS8-5), that instead yielded yellow pigmented colonies on PDA, were resolved as P. biglobosus subclade 'brassicae' (Pbb). Newly obtained sequences were deposited to GenBank, and reference isolates were deposited into both the CABI (IMI) and CHAP live culture collections (Table 1).

The pathogenicity profiles of three newly obtained tester isolates (Pbc: 21WAS1-2, 21WAS7-1; Pbb: 21WAS8-4) were evaluated on live plants under greenhouse conditions in Surrey in July/August 2021, with OSR (Brassica napus, cv. Westar), cabbage (B. oleracea), and pak choi (B. rapa cv. Yuushou F1) plants 14 days old at time of testing, and wasabi plants having leaves $\sim 10 \mathrm{~cm}$ diameter. Conidial suspensions were harvested from PDA cultures (grown at $20{ }^{\circ} \mathrm{C}$ in the dark for $8-12$ weeks) and adjusted to $10^{7}$ conidia / $\mathrm{mL}$ using SDW. Four cotyledons of each of the Brassica hosts (left lobes only), and three wasabi leaves (both left and right sides) were gently wounded (with a sterile cocktail stick) and point inoculated with either $10 \mu \mathrm{l}$ isolate conidial suspension or treated with $10 \mu \mathrm{l}$ SDW. Plants were sealed in polyethylene bags to maintain high humidity for $48 \mathrm{~h}$. After one week for OSR, cabbage and pak choi cotyledons, and two weeks for wasabi leaves, Phoma lesions were evident on all hosts at points inoculated with $\mathrm{Pbc}$ or $\mathrm{Pbb}$ isolates, but not SDW-treated controls. Representative pathogenicity testing results are shown in Fig. 3. Subsequently, re-isolation of $\mathrm{Pbb} /$ $\mathrm{Pbc}$ was attempted from surface sterilized lesion margins (i.e. fungal inoculated) or SDW treatment points (i.e. controls) from OSR cotyledons and wasabi leaves (Fig. 4, see legend for additional information). Isolates, the species and subclade identities of which were confirmed as either $\mathrm{Pbb} / \mathrm{Pbc}$, based initially on colony morphology and subsequently by ITS rDNA sequencing were successfully cultured from lesions that developed after inoculation. Cultures of Pbc were obtained from lesions that developed after inoculation with $\mathrm{Pbc}$ isolates (i.e. 21WAS1-2, 21WAS71); cultures of $\mathrm{Pbb}$ were obtained from lesions that developed after inoculation with the Pbb isolate (i.e. 21WAS8-4). Last, no fungi grew from SDW-treated controls, thus completing Koch's postulates.

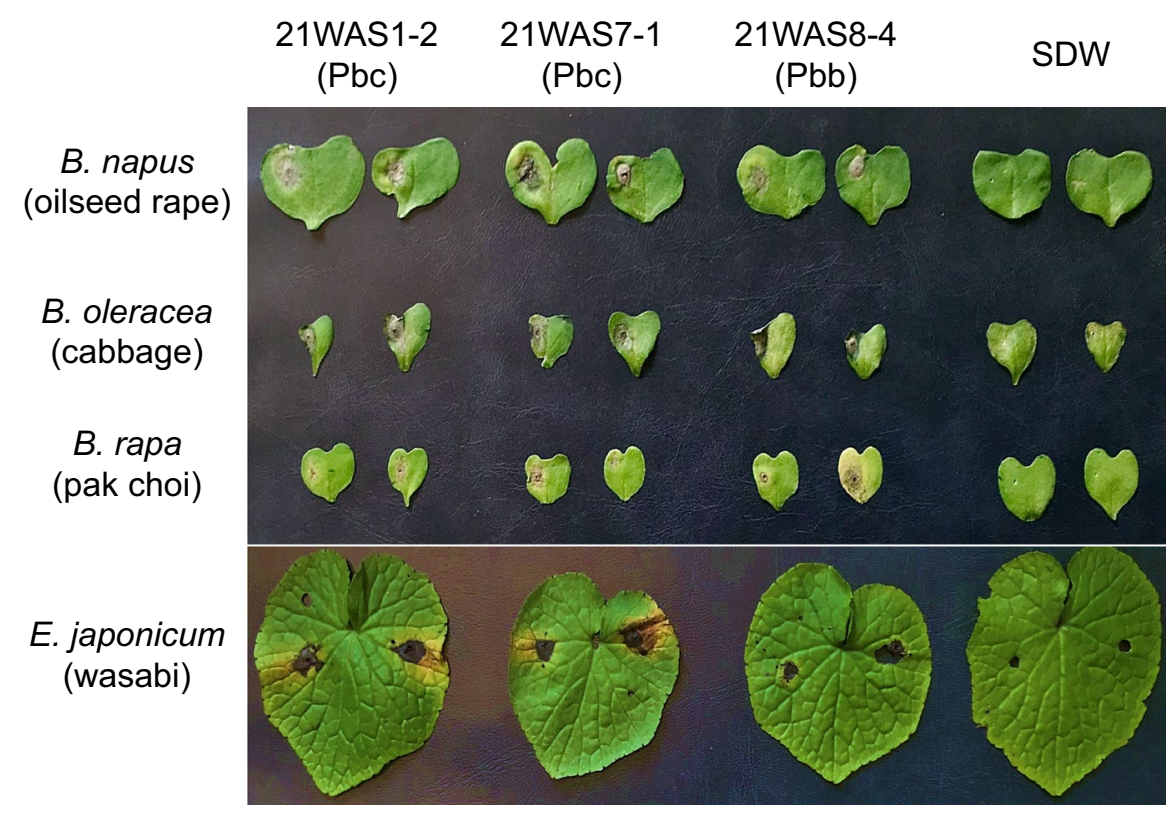

Fig. 3 Greenhouse pathogenicity testing of Plenodomus biglobosus subclades 'brassicae' (Pbb) and 'canadensis' (Pbc) originally obtained from diseased Eutrema japonicum (wasabi) leaves in the UK. Two representative Brassica napus (oilseed rape), B. oleracea (cabbage), and B. rapa (pak choi) cotyledons are shown at 1 week post inoculation (wpi) for each iso- late or sterile distilled water (SDW) treatment tested (note that cotyledons were tested on left lobes only). A representative wasabi leaf is shown at 2 wpi for each isolate or SDW treatment tested (note both sides of wasabi leaves were tested). All plants were wounded prior to either isolate inoculation or SDW treatment 


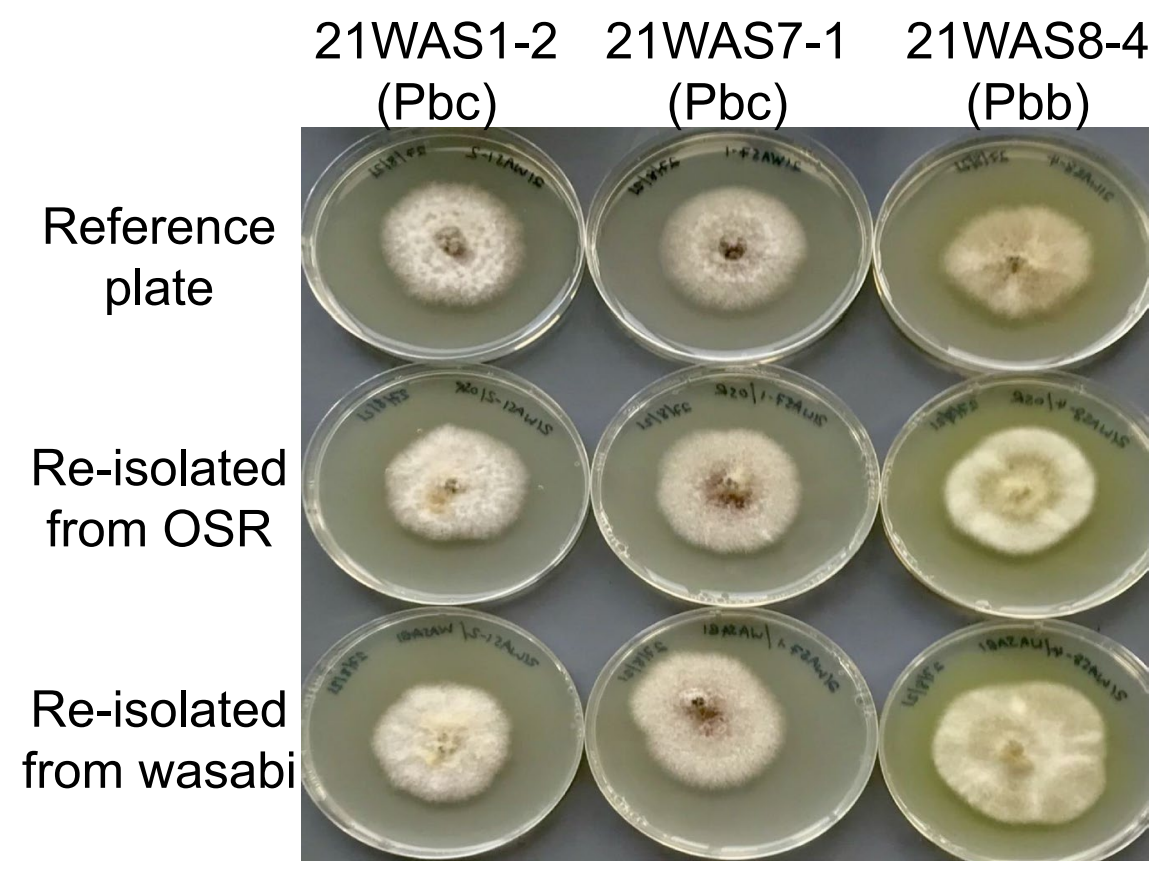

Fig. 4 Re-isolation of Plenodomus biglobosus subclades 'brassicae' $(\mathrm{Pbb})$ or 'canadensis' ( $\mathrm{Pbc}$ ) from lesion margins of artificially inoculated Brassica napus (oilseed rape, OSR) and Eutrema japonicum (wasabi) leaves. The three isolates used for pathogenicity testing were cultured from diseased wasabi leaves (tester isolate reference plates, top row), caused disease on artificially inoculated leaves of both oilseed rape and wasabi (see Fig. 2), and were subsequently re-isolated on

To date, $\mathrm{Pbc}$ has been reported from Brassica species (and also Thlaspii arvense) in Australia, Canada, China, Mexico and the USA (e.g. Mendes-Pereira et al., 2003; Van de Wouw et al., 2008; Dilmaghani et al., 2009, 2010; Luo et al., 2021). However, the present study extends the known geographic range of $\mathrm{Pbc}$ to now include Europe, having been found at two geographically distinct UK sites (Southern England and Northern Ireland). Moreover, this study also represents, to the best of the authors' knowledge, new discoveries for both $\mathrm{Pbb}$ and $\mathrm{Pbc}$ as causal agents of Phoma disease on wasabi plants. Prior to this study, based on available sequence data, $P$. biglobosus subclade 'occiaustralensis' appears to be the predominant subclade on Phoma-symptomatic wasabi, with reports from Canada, New Zealand and Taiwan (de Gruyter et al., 2013; Johnston et al., 2017; Punja et al., 2017). Thus, it is evident that multiple genetic subclades of $P$. biglobosus are pathogenic to wasabi. potato dextrose agar (PDA) plates from lesions that had developed inoculated OSR (middle row) and wasabi (bottom row) leaves. Plates shown were incubated at $20{ }^{\circ} \mathrm{C}$ in the dark for 10 days. Note the production of bright yellow pigmented colonies for Pbb isolate 21WAS8-4 but not Pbc isolates 21WAS1-2 or 21WAS7-1. Species and subclade identities of the reisolated cultures were confirmed by sequencing of the ITS rDNA region (data not shown)

In the present study, petiole and stem lesions were also observed occasionally on naturally infected wasabi plants suggestive of systemic infection of this host by $P$. biglobosus. However, as fungal isolation was attempted in the present study only from foliar lesions, and not from those on petioles/stems, further work is required to investigate the infection strategy of $P$. biglobosus on wasabi. Additional research is also now needed to explore the geographic distribution, comparative epidemiology, taxonomic status and Brassica crop health implications of the P. biglobosus subclades. In recent years, there is evidence that $P$. biglobosus has become an increasingly problematic important pathogen of UK OSR crops (Huang et al., 2014). Previously, the only P. biglobosus subclade reported in Europe has been Pbb (e.g. Liu et al., 2014; Mendes-Pereira et al., 2003). One hypothesis for the reported increase in $P$. biglobosus importance is that additional genetic subclades, including $\mathrm{Pbc}$, may now 
be present. Additional monitoring surveys are now required understand the geographic distribution of the $P$. biglobosus subclades present in current pathogen populations, both on wild and cultivated (particularly OSR) brassicas from throughout the British Isles and continental Europe. Molecular-based approaches will be required, as although some previous studies have used pigment production in agar culture as a criterion for discrimination of $P$. lingam / P. biglobosus (Williams \& Fitt, 1999), given that only some $P$. biglobosus isolates appear to produce such pigment, this is insufficient for species / subclade discrimination.

Acknowledgements This work was partly supported by funding from the Smart Crop Protection strategic programme (BBS/OS/CP/000001) funded through the BBSRC's Industrial Strategy Challenge Fund, and the OREGIN project (CH0110) funded by Defra.

\section{Declarations}

The authors declare that the research complies with ethical standards.

Conflicts of interest The authors have no conflicts of interest to declare that are relevant to the content of this article.

Open Access This article is licensed under a Creative Commons Attribution 4.0 International License, which permits use, sharing, adaptation, distribution and reproduction in any medium or format, as long as you give appropriate credit to the original author(s) and the source, provide a link to the Creative Commons licence, and indicate if changes were made. The images or other third party material in this article are included in the article's Creative Commons licence, unless indicated otherwise in a credit line to the material. If material is not included in the article's Creative Commons licence and your intended use is not permitted by statutory regulation or exceeds the permitted use, you will need to obtain permission directly from the copyright holder. To view a copy of this licence, visit http://creativecommons.org/licenses/by/4.0/.

\section{References}

de Gruyter, J., Woudenberg, J. H. C., Aveskamp, M. M., Verkley, G. J. M., Groenewald, J. Z., \& Crous, P. W. (2013). Redisposition of Phoma-like anamorphs in Pleosporales. Studies in Mycology, 75, 1-36. https://doi.org/10.3114/ $\operatorname{sim} 0004$
Dilmaghani, A., Balesdent, M. H., Didier, J. P., Wu, C., Davey, J., Barbetti, M. J., Li, H., Moreno-Rico, O., Phillips, D., Despeghel, J. P., Vincenot, L., Gout, L., \& Rouxel, T. (2009). The Leptosphaeria maculans-Leptosphaeria biglobosa species complex in the American continent. Plant Pathology, 58, 1044-1058. https://doi.org/10. 1111/j.1365-3059.2009.02149.x

Dilmaghani, A., Balesdent, M. H., Rouxel, T., \& Moreno-Rico, O. (2010). First report of Leptosphaeria biglobosa (blackleg) on Brassica oleracea (cabbage) in Mexico. Plant Disease, 94, 791. https://doi.org/10.1094/PDIS-94-6-0791C

Huang, Y. J., Karandeni-Dewage, C. S., \& Fitt, B. D. L. (2014). Importance of Leptosphaeria biglobosa as a cause of phoma stem canker on winter oilseed rape in the UK. Aspects of Applied Biology, 127, 117-122.

Johnston, P. R., Park, D., Ho, W. W. H., \& Alexander, B. J. R. (2017). Genetic validation of historical plant pathology records - a case study based on the fungal genus Phoma from the ICMP culture collection. Plant Pathology, 66, 1424-1431. https://doi.org/10.1111/ppa.12728

Liu, Z., Latunde-Dada, A. O., Hall, A. M., \& Fitt, B. D. L. (2014). Phoma stem canker disease on oilseed rape (Brassica napus) in China is caused by Leptosphaeria biglobosa 'brassicae.' European Journal of Plant Pathology, 140, 841-857. https://doi.org/10.1007/s10658-014-0513-7

Luo, T., Li, G., \& Yang, L. (2021). First report of Leptosphaeria biglobosa 'canadensis' causing blackleg on oilseed rape (Brassica napus) in China. Plant Disease. https://doi. org/10.1094/PDIS-12-20-2735-PDN

Mendes-Pereira, E., Balesdent, M.-H., Brun, H., \& Rouxel, T. (2003). Molecular phylogeny of the Leptosphaeria maculans-L. biglobosa species complex. Mycological Research, 107, 1287-1304. https://doi.org/10.1017/S0953 756203008554

Punja, Z. K., Chandanie, W. A., Chen, X., \& Rodríguez, G. (2017). Phoma leaf spot of wasabi (Wasabia japonica) caused by Leptosphaeria biglobosa. Plant Pathology, 66, 480-489. https://doi.org/10.1111/ppa.12589

Van de Wouw, A. P., Thomas, V. L., \& Cozijnsen, a. j., Marcroft, S. J., Salisbury, P. A., and Howlett, B. J. (2008). Identification of Leptosphaeria biglobosa 'canadensis' on Brassica juncea stubble from northern New South Wales, Australia. Australasian Plant Disease Notes, 3, 124-128. https://doi.org/10.1007/BF03211265

White, T. J., Bruns, T., Lee, S., \& Taylor, J. (1990). Amplification and direct sequencing of fungal ribosomal RNA genes for phylogenetics. PCR Protocols: A Guide to Methods and Applications, 18, 315-322.

Williams, R. H., \& Fitt, B. D. L. (1999). Differentiating A and B groups of Leptosphaeria maculans, causal agent of stem canker (blackleg) of oilseed rape. Plant Pathology, 48, 161-175. https://doi.org/10.1046/j.1365-3059.1999. 00333.x 